\title{
Elevated calcium and activation of trypsinogen in rat pancreatic acini
}

T W Frick, C Fernández-del-Castillo, D Bimmler, A L Warshaw

\begin{abstract}
Background-Acute pancreatitis associated with hypercalcaemia has been described in humans and experimental animals. It has been demonstrated that calcium dose dependently accelerates trypsinogen activation, and it is generally believed that ectopic activation of digestive enzymes is an early event in the pathophysiology of acute pancreatitis.

Aims and methods-Trypsinogen activation peptide (TAP) was measured in isolated rat pancreatic acini exposed to elevated extracellular calcium in order to investigate the association between calcium and trypsinogen activation in living cells. TAP was determined in the culture medium either before (extracellular compartment) or after (intracellular compartment) cell homogenisation.

Results-Neither secretory stimulation nor elevated calcium alone caused an increase in TAP levels. Maximal cerulein or carbachol stimulation superimposed on high medium calcium, however, significantly increased intracellular trypsinogen activation twofold. This increase was inhibited by either $N^{\mathrm{G}}$-monomethyl-Larginine (L-NMMA) or verapamil. Acinar cell morphology and function remained intact as demonstrated by electron microscopy and secretagogue dose-response studies.

Conclusions-These results support the hypothesis that increased intracellular trypsinogen activation is an early step in the pathogenesis of hypercalcaemia induced pancreatitis. The model may have a bearing on other types of pancreatitis as elevated cytosolic calcium is thought to be an early event in the pathogenesis of acute pancreatitis in general.
\end{abstract}

(Gut 1997; 41: 339-343)

Keywords: hypercalcaemia; pancreatitis pathogenesis; serine proteases; acute pancreatitis

There is increasing evidence that elevated calcium in pancreatic acinar cells is an important early step in the development of acute pancreatitis. ${ }^{1}$ We previously used hypercalcaemia as a model to study the effects of elevated calcium in the development of pancreatitis in vivo. In humans, acute pancreatitis was found to be associated with hypercalcaemic conditions, such as hyperparathyroidism or therapeutic calcium administration. ${ }^{2-4}$ In a rat model acute pancreatitis was induced by bolus injection of calcium. ${ }^{5}$ Other experimental protocols used low dose continuous infusions of calcium leading to a twofold increase in serum ionised calcium. Morphological changes of early acute pancreatitis were seen in several animal species. ${ }^{6} 7$ It was shown that hypercalcaemia induced a secretory block and accumulation of digestive zymogens within the pancreatic acinar cell. ${ }^{8}$ Zymogen activation, in particular trypsinogen, in homogenates of pancreatic tissue after calcium injection, suggested that the combination of zymogen accumulation and increased calcium leads to increased intrapancreatic trypsinogen activation as a very early step in the pathogenesis of acute hypercalcaemia induced pancreatitis. $^{58}$

Despite this evidence it remained unclear whether the ectopic zymogen activation occurred as an initial step in the pathogenesis of pancreatitis, or whether it was the result of acinar cell injury. In the work reported in the present paper, the effect of elevated environmental calcium on trypsinogen activation was investigated more directly. We used an in vitro model of isolated pancreatic acini exposed to elevated medium calcium. As a marker for trypsinogen activation we measured trypsinogen activation peptide (TAP), the $\mathrm{N}$-terminal of trypsinogen which is cleaved to active trypsin. ${ }^{9}{ }^{10}$ The five amino acid carboxyl end of TAP is highly preserved among species, and the antibody against TAP used in the competitive ELISA is highly specific. Quantification of TAP is a direct measurement of the amount of activated trypsinogen as one TAP molecule is generated for each molecule of trypsinogen cleaved to trypsin.

\section{Materials and Methods}

ACINAR CELL SUSPENSIONS

For each experiment three male Wistar rats $(80-100 \mathrm{~g})$ fasted overnight were used. They were sacrificed in $\mathrm{CO}_{2}$, the pancreas was quickly excised in the cold room, and pancreatic acini were prepared by collagenase digestion. ${ }^{11}$ Collagenase (type CLS 4, $1000 \mathrm{U} /$ $\mathrm{ml}$ ) was purchased from Worthington Biochemical Corporation, Freehold, New Jersey, USA. After digestion the cells were incubated at $4^{\circ} \mathrm{C}$ in medium containing HEPES $12.5 \mathrm{mM}, \mathrm{NaHCO}_{3} 5.0 \mathrm{mM}, \mathrm{NaCl} 125 \mathrm{mM}$, $\mathrm{KCl} 5.0 \mathrm{mM}, \mathrm{KH}_{2} \mathrm{PO}_{4} 1.2 \mathrm{mM}, \mathrm{MgSO}_{4}$ $1.2 \mathrm{mM}$, D-glucose $5.0 \mathrm{mM}$, aprotinin $0.01 \mathrm{mg} / \mathrm{ml}$, soybean trypsin inhibitor $0.1 \mathrm{mg} /$ $\mathrm{ml}$, BSA $0.1 \%, \mathrm{pH}$ adjusted to 7.40 with $\mathrm{NaOH}$, and either $\mathrm{CaCl}_{2} 1.2 \mathrm{mM}$ (physiological concentration) with additional $\mathrm{NaCl}$ $3.8 \mathrm{mM}$, or $\mathrm{CaCl}_{2} 5.0 \mathrm{mM}$ (hypercalcaemia)
Accepted for publication 4 March 1997 


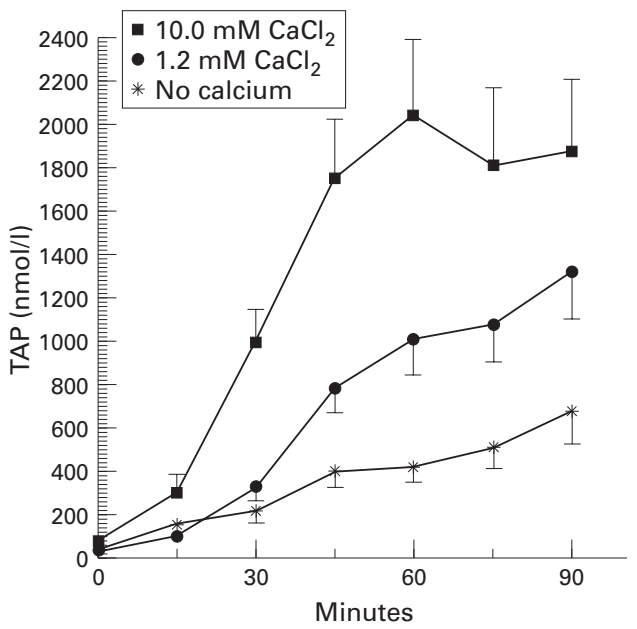

Figure 1: Effect of calcium on trypsinogen activation. Calcium accelerates TAP generation dose dependently. After 30 minutes the points of all three curves are significantly different (mean (SD); $n=4 ; p<0.05$ ).

(all chemicals were from Sigma Chemical Company, St Louis, Missouri, USA, unless otherwise specified). We tested a calcium concentration of $5.0 \mathrm{mM}$ because previous studies on pancreatic lobules indicated that this concentration maximally enhanced acinar secretion without tissue damage. ${ }^{72}$ Cell viability was tested with the trypan blue exclusion method immediately after preparation of acini by collagenase digestion. Preparations were accepted for study only if more than $95 \%$ of the cells excluded the dye.

STUDIES OF AMYLASE SECRETION AND

TRYPSINOGEN ACTIVATION

The cells were incubated at $37^{\circ} \mathrm{C}$ in 24 -well cell culture plates (Falcon 3047, Becton Dickinson Labware, Lincoln Park, New Jersey, USA) with $500 \mu \mathrm{l}$ of cell suspension in each well, and gassed with $100 \% \mathrm{O}_{2}$. After $15 \mathrm{~min}$ utes of preincubation, cerulein, carbachol, $N^{\mathrm{G}}$-monomethyl-L-arginine (L-NMMA), and verapamil were added. All measurements were performed in duplicate and controls were

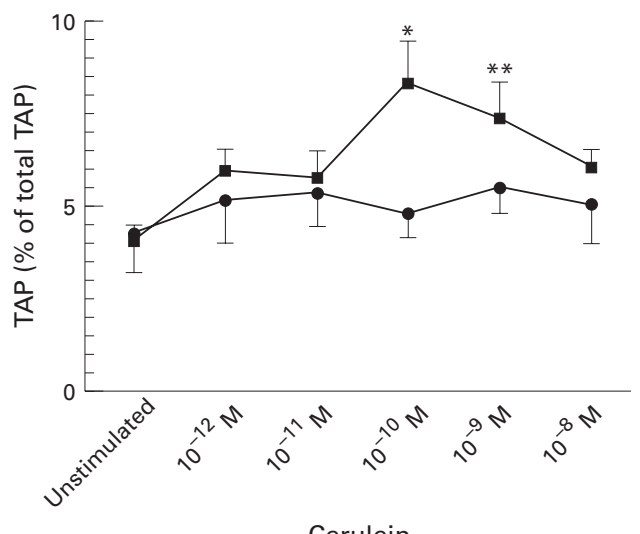

Cerulein

Figure 2: Effect of elevated calcium on TAP levels (mean $(S E M) ; n=6)$. The increase in TAP of cells stimulated with $10^{-10} \mathrm{M}$ cerulein is significant $\left({ }^{*} p<0.05\right)$ compared with all preparations except $10^{-9} \mathrm{M}$ cerulein; the effect of the $10^{-9} \mathrm{M}$ cerulein preparation is significant compared with unstimulated acini $\left({ }^{*} p=0.02\right)$ (closed circles $=1.2 \mathrm{mM}$ $\mathrm{CaCl}_{2}$; closed squares $\left.=5.0 \mathrm{mM} \mathrm{(aCl}\right)$.
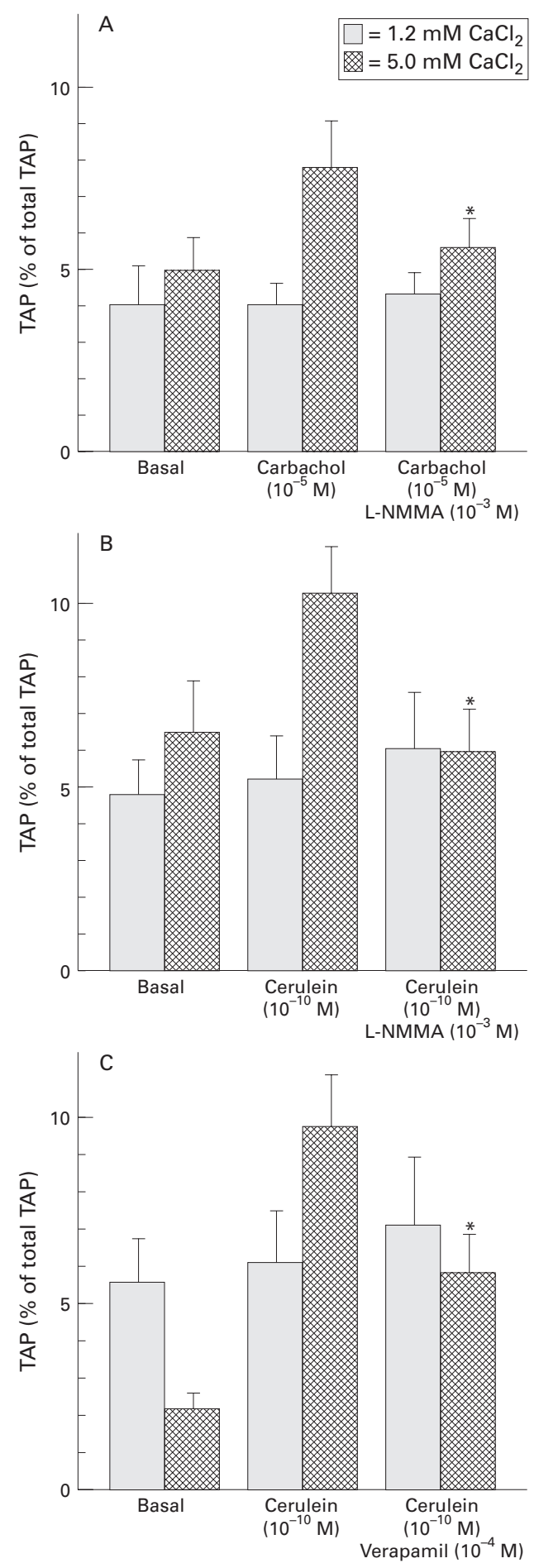

Figure 3: Effect of $L-N M M A$ or verapamil on intracellular TAP levels. Each graph represents an individual set of experiments (mean (SEM), $n=6$ ). TAP levels of acini incubated in $5.0 \mathrm{mM}$ calcium and stimulated with $10^{-5} \mathrm{M}$ carbachol $(A)$ or $10^{-10} \mathrm{M}$ cerulein $(B, C)$ were significantly reduced when $10^{-3} \mathrm{M} L-N M M A(A, B)$ or $10^{-4} \mathrm{M}$ verapamil $(C)$ was added $\left({ }^{*} p<0.05\right)$.

run on the same plates. At the end of the one hour incubation period $100 \mu \mathrm{l}$ of medium was removed, $400 \mu \mathrm{l}$ of Tris (0.1 M, pH 8.9) and Triton X-100 (2\%) was added for cell homogenisation, and the plate was incubated on a mini shaker for 30 minutes at room temperature. 


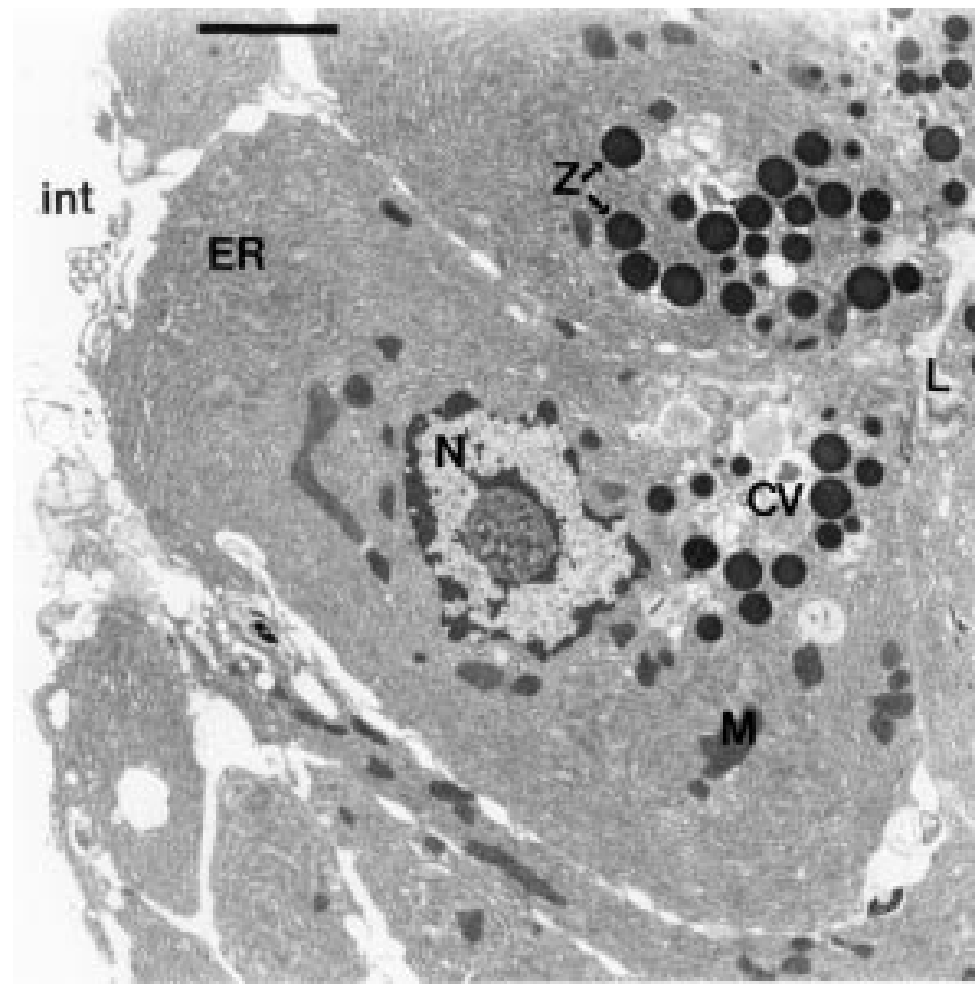

Figure 4: Electron micrograph of an isolated acinar preparation after one hour's incubation at $37^{\circ} \mathrm{C}$ in medium containing $5.0 \mathrm{mM}$ calcium and $10^{-10} \mathrm{M}$ cerulein. There are no signs of acinar cell damage with intact acinar cell morphology, and normal nucleus $(N)$, mitochondria (M), and endoplasmic reticulum (ER). Signs of maximal cerulein induced stimulation are an increased number of condensing vacuoles $(C V)$ in an enlarged Golgi apparatus and a reduced number of zymogen granules $(Z)$ (Bar $=4 \mu \mathrm{M} ; L=$ acinar lumen; int = interstitial space).
STUDIES OF TRYPSINOGEN ACTIVATION KINETICS To examine trypsinogen autoactivation $3 \mathrm{mg} /$ $\mathrm{ml}$ bovine trypsinogen was dissolved in incubation medium, $\mathrm{pH}$ adjusted to 7.40 , with either no calcium or $1.2 \mathrm{mM}$ or $10.0 \mathrm{mM} \mathrm{CaCl}_{2}$. The preparation was incubated at $37^{\circ} \mathrm{C}$ in 24 -well cell culture plates $(1000 \mu \mathrm{l}$ per plate $)$ and $10 \mu \mathrm{l}$ aliquots were removed at 15 minute intervals. The aliquots were boiled immediately in $1000 \mu \mathrm{l}$ medium containing $0.02 \mathrm{M}$ EDTA before determination of TAP.

DETERMINATION OF AMYLASE AND TRYPSINOGEN ACTIVATION PEPTIDE

Amylase was measured in the medium and the homogenate with the Phadebas amylase test (Pharmacia Diagnostics AB, Uppsala, Sweden).

To determine free TAP a competitive ELISA immunoassay was used as described elsewhere ${ }^{10}$ with the following modifications: the antiTAP antiserum (R7103/4/5) was diluted $1 / 400$ in assay buffer, and the alkaline phosphatase-extravidin conjugate was used in a $1 / 750$ dilution. To ascertain the relationship of the observed TAP levels with the total trypsinogen pool, the homogenates were incubated with enterokinase $(1 \mathrm{U} / \mathrm{ml})$ for one hour at $37^{\circ} \mathrm{C}$ to convert all trypsinogen to equimolar quantities of trypsin and TAP as described previously. ${ }^{9}{ }^{10}$ The total TAP after this processing represents a measure of the trypsinogen content of the cells. TAP levels can then be expressed as a function of total trypsinogen to indicate the degree of activation.
ELECTRON MICROSCOPY

After the incubation period, acini were immediately fixed in glutaraldehyde $(3 \%)$, formaldehyde $(2 \%)$, and sodium cacodylate $(0.1 \mathrm{M})$ for one hour at $4^{\circ} \mathrm{C}$, washed twice in $0.1 \mathrm{M}$ sodium cacodylate, and embedded in Epon after dehydration in graded series of alcohol. Thin sections were stained on the grid with uranyl acetate and lead citrate and viewed with a JEOL 100-CX electron microscope.

\section{STATISTICAL ANALYSIS}

Statistical calculations were performed with InStat software (Graphpad, San Diego, California, USA) using the two tailed Student's $t$ test for paired data for interpretation of the results. Data are presented as mean (SEM) unless indicated otherwise.

\section{Results}

STUDIES OF IN VITRO TRYPSINOGEN ACTIVATION KINETICS

The effect of calcium on spontaneous cleavage of trypsinogen was evaluated by measuring the appearance of TAP in trypsinogen solutions ( $3 \mathrm{mg} / \mathrm{ml}$ medium) containing graded calcium concentrations. Figure 1 shows that there was acceleration of trypsinogen activation at higher calcium concentrations.

STUDIES OF CELLULAR TRYPSINOGEN ACTIVATION Extracellular TAP was less than $0.5 \%$ of total TAP at both concentrations of calcium in the medium, and no difference between the preparations was found (data not shown). Neither secretory stimulation nor incubation in high calcium $(5.0 \mathrm{mM})$ alone caused an increase in intracellular TAP levels with respect to levels found in physiological calcium $(1.2 \mathrm{mM})$. However, elevated calcium superimposed on either maximal or supramaximal cerulein stimulation significantly increased intracellular TAP (fig 2). Carbachol at maximal stimulatory concentrations similarly induced a significant increase in intracellular TAP concentration in the high calcium medium, but not at physiological calcium levels (fig 3). Verapamil and L-NMMA significantly inhibited the TAP increase by maximal carbachol and cerulein stimulation (fig 3).

\section{MORPHOLOGY}

Electron microscopy of acini after incubation in $5.0 \mathrm{mM}$ calcium and $10^{-10} \mathrm{M}$ cerulein revealed powerful stimulation as indicated by enlarged Golgi apparatus, increased number of condensing vacuoles, and decreased number of zymogen granules (fig 4). Acinar cell ultrastructure remained intact with normal mitochondria, cell nucleus, and cell membrane.

\section{EFFECT OF ELEVATED CALCIUM ON AMYLASE} SECRETION

The effect of elevated extracellular calcium on stimulated amylase secretion was investigated with carbachol and cerulein. The doseresponse curves with carbachol and cerulein showed a significant increase in amylase output at maximal stimulation in elevated medium 

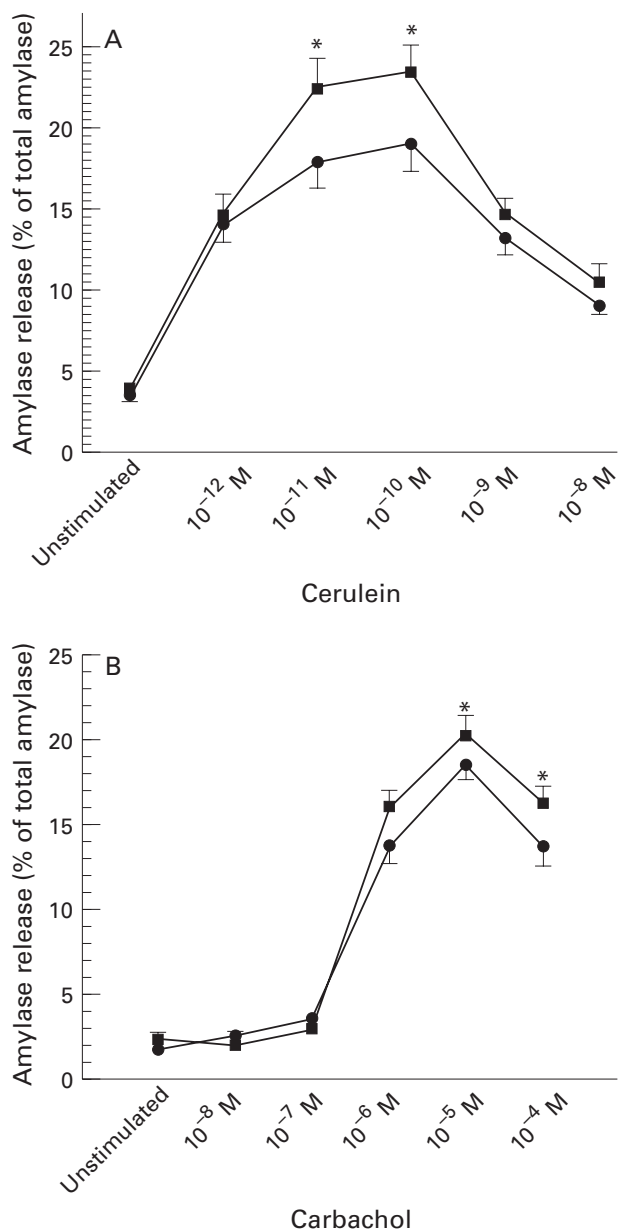

Figure 5: Effect of calcium on amylase release of cerulein stimulated pancreatic acini (mean $(S E M) ; n=6)$ and carbachol stimulated pancreatic acini (mean (SEM); $n=8$ ). In both medium calcium concentrations (closed circles $=1.2 \mathrm{mM} \mathrm{CaCl}$; closed squares $=5.0 \mathrm{mM} \mathrm{CaCl}$ ), maximal amylase secretion occurred at $10^{-10} \mathrm{M}$ cerulein and $10^{-5} \mathrm{M}$ carbachol, respectively, and stimulation with higher doses of cerulein or cabachol (supramaximal stimulation) inhibited amylase release. Extracellular calcium at $5.0 \mathrm{mM}$ significantly enhanced submaximally and maximally cerulein stimulated and maximally and supramaximally carbachol stimulated amylase output $\left({ }^{*} p<0.05\right)$. Supramaximal stimulation reduced amylase release both absolutely and relatively compared with acinar cells in physiological calcium.

calcium (fig 5). With supramaximal agonist concentrations amylase output decreased in both medium calcium concentrations.

\section{Discussion}

The exocrine pancreas produces, stores, and exports a series of powerful digestive enzymes in precursor forms. One of these, the serine protease precursor trypsinogen, once it has been activated to trypsin, is capable of activating its own precursor and all other pancreatic serine proteases. ${ }^{13}$ As ectopic trypsinogen activation may initiate a cascade of protease activation within the pancreas leading to autodigestion of the gland, trypsin is thought to play a key role in the pathogenesis of acute pancreatitis. $^{14}$

Based on the following observations we hypothesised that the possible mechanism of acute pancreatitis associated with hypercalcae- mia is a calcium triggered intrapancreatic activation of trypsinogen: (1) calcium accelerates generation of trypsin from trypsinogen in vitro in a dose dependent fashion as documented by direct determination of trypsin activity, ${ }^{15-17}$ and in this study by measuring TAP. (2) Elevated extracellular calcium increases cytosolic calcium in isolated pancreatic acini in proportion to the extracellular calcium level. ${ }^{18}$ (3) There is extensive clinical and experimental evidence that elevated serum calcium concentrations induce acute pancreatitis in vivo. ${ }^{2-8}$

To test the hypothesis, we exposed isolated pancreatic acini with or without stimulation to elevated extracellular calcium. Using Fura-2 as a marker for spectrophotometric measurement of intracellular calcium, we confirmed that the cytosolic calcium increases in response to increased extracellular calcium concentrations (data not shown). After one hour TAP was determined in the medium before (extracellular compartment) and after (intracellular compartment) lysis of all acinar cells. In the extracellular compartment, the concentrations of TAP were below $1 \%$ of the total and there were no differences seen in preparations stimulated with cerulein or exposed to high calcium. This indicates that intracellular TAP is not secreted into the medium in substantial amounts. It also indicates that there is no significant activation of secreted trypsinogen in the extracellular compartment in this experimental setting.

The mean TAP concentration in the intracellular compartment of unstimulated cells exposed to physiological calcium concentrations was close to $5 \%$. Leach et $a l^{19}$ have demonstrated a comparable amount of active intracellular proteases in unstimulated pancreatic acini, although no active trypsin was found. This may represent spontaneous intracellular protease activation. ${ }^{13}$ It may however indicate that intracellular trypsin is immediately neutralised by local protease inhibitors, thereby maintaining a stable state. ${ }^{13}$ The advantage of TAP determination is that it demonstrates trypsinogen activation irrespective of whether the resulting trypsin is active or blocked by inhibitors. However, because the intracellular metabolism of TAP is unknown, the measured TAP level may also be the result of TAP accumulation while trypsinogen actually activates at a lower rate.

Elevation of extracellular calcium alone did not generate an increase in intracellular TAP, but when the acinar cells were stimulated with cerulein a rise in intracellular TAP was noted in cells exposed to high environmental calcium and the degree of TAP production was directly related to the cerulein level. The dose-response curve was biphasic with a peak at maximal cerulein stimulation. The increase was significant compared with both maximally stimulated acinar cells in $1.2 \mathrm{mM}$ calcium and unstimulated cells in $5.0 \mathrm{mM}$ calcium

Another significant rise in intracellular TAP was seen when cells exposed to high extracellular calcium were maximally stimulated with carbachol. As both maximal secretory stimulation and elevated extracellular calcium increase cytosolic calcium, ${ }^{18}$ it is possible that a 
concordant effect caused the intracellular calcium concentration to rise beyond a critical level above which trypsinogen autoactivation was accelerated. It is however unclear why the increase in TAP was less pronounced during supramaximal stimulation, although equally high calcium spikes have been demonstrated. ${ }^{20}$ A possible explanation is that, although the calcium spikes are equally high, the duration of the calcium spikes is shorter and thus the absolute calcium concentrations may be lower. ${ }^{20}$

To test whether the increase in TAP is related to the increase in intracellular calcium, we used the calcium blockers L-NMMA and verapamil. The nitric oxide synthetase inhibitor L-NMMA has been shown to reduce significantly ${ }^{45} \mathrm{Ca}^{2+}$ uptake in pancreatic acini stimulated by carbachol and is thought to decrease cytosolic calcium concentration. ${ }^{21}$ Verapamil blocks calcium uptake through voltage gated calcium channels. ${ }^{22}$ Although a direct effect on cells without voltage gated calcium channels, such as pancreatic acinar cells, ${ }^{23}$ has not been demonstrated, verapamil has an inhibitory effect on agonist stimulated amylase release which is partially reversible by increasing the extracellular calcium concentration. ${ }^{24} 25$ In our studies, both compounds inhibited the increase in intracellular TAP induced by maximal cerulein or carbachol stimulation.

To determine whether trypsinogen activation is the result of acinar cell injury or an event that precedes acinar cell damage, we looked at acinar cell ultrastructure and acinar cell function. Electron microscopy of maximally stimulated cells in high extracellular calcium revealed signs of intense stimulation, such as increased numbers of condensing vacuoles and enlarged Golgi apparatus, but normal chromatin structure, mitochondria, and endoplasmic reticulum, indicating intact acinar cell structure. Study of acinar cell function as determined by amylase secretion in response to cerulein or carbachol showed that the cells responded to high calcium by enhanced amylase output with an intact dose-response curve. ${ }^{26}$ This demonstrates undisturbed acinar cell response to stimuli and intact acinar function.

In this study, we have demonstrated increased intracellular TAP production in response to elevated extracellular calcium and maximal stimulation in morphologically and functionally intact rat pancreatic acini. The results support the hypothesis that increased intracellular trypsinogen activation may be an initial step in the development of hypercalcaemia induced pancreatitic tissue damage. The model may also have a bearing on other types of pancreatitis: it is becoming increasingly apparent that an increase in cytosolic calcium might be a key event in the pathogenesis of acute pancreatitis in general.

We would like to acknowledge the great help and effort of D Max A Spycher in the preparation of the electron microscopy samples, and of Uma Mandavilli and Regula Gassmann for their enormous help in preparing the acinar cells and measuring TAP. The work was supported in part by a grant from the Schweizerische Stiftung für Medizinisch Biologische Stipendien, the Kommission zur Förderung des Akademischen Nachwuchses der Universität Zürich, and the Swiss National Foundation.

1 Ward JB, Peterson OH, Jenkins SA, Sutton R. Is an elevated concentration of acinar cytosolic free ionized calcium the rigger for acute pancreatitis? Lancet 1995; 346: 1016-9.

2 Fernández-del Castillo C, Harringer W, Warshaw AL, Vlahakes GJ, Koski G, Zaslavsky AM, et al. Risk factors for pancreatic cellular injury after cardiopulmonary bypass. $N$ Engl f Med 1991; 325: 382-7.

3 Frick TW, Speiser DE, Bimmler D, Largiadèr F. Druginduced acute pancreatitis; further criticism. Dig Dis 1993; 11: $113-32$.

4 Frick TW, Fryd DS, Sutherland DER, Goodale RL, Simmons RL, Najarian JS. Hypercalcemia associated with pancreatitis and hyperamylasemia in renal transplant recipients. Data from the Minnesota randomized trial of recipients. Data from the Minnesota randomized trial of cyclosporine versus an
Surg 1987; 154: 487-9.

5 Mithöfer K, Fernández-del Castillo C, Frick TW, Lewandrowski KB, Rattner DW, Warshaw AL. Acute hypercalcemia causes acute pancreatitis and ectopic trypsinogen activation in the rat. Gastroenterology 1995; 109: 239-46.

6 Frick TW, Hailemariam S, Heitz PU, Largiadèr F, Goodale RL. Acute hypercalcaemia induces acinar cell necrosis and intraductal precipitates in the pancreas of cat and guinea pig. Gastroenterology 1990; 98: 1675-81.

7 Frick TW, Wiegand D, Bimmler D, Fernández-del Castillo C, Rattner DW, Warshaw AL. A rat model to study hypercalcemia-induced pancreatitis. Int $\mathcal{F}$ Pancreatol 1994; 15: $91-6$.

8 Frick TW, Mithöfer K, Fernández-del Castillo C, Rattner DW, Warshaw AL. Hypercalcemia causes acute pancreatitits by pancreatic secretory block, intracellular zymogen tits by pancreatic secretory block, intracellular zymogen 167-72.

9 Hurley PR, Cook A, Jehanli A, Austen BM, Hermon-Taylor J. Development of radioimmunoassays for free tetra-Laspartyl-L-lysine trypsinogen activation peptides (TAP). $\mathcal{F}$ Immunol Methods 1988; 111: 195-203.

10 Mithöfer K, Fernández-del Castillo C, Mandavilli U, Rattner DW, Warshaw AL. Quantitative assay of trypsinogen by measurement of cleaved activation peptide after activation with enterokinase. Anal Biochem 1995; 230: 348-50.

11 Bruzzone R, Halban PA, Ginovci A, Trimble ER. A new, rapid, method for preparation of dispersed pancreatic acini. Biochem f 1985; 226: 621-4.

12 Layer P, Hotz J, Cherian L, Goebell H. In vitro stimulation of pancreatic enzyme discharge by elevated extracellular calcium concentrations. Gut 1987; 28: 1215-20.

13 Rinderknecht H. Pancreatic secretory enzymes. In: Go VLW, DiMagno EP, Gardner JD, Lebenthal E, Reber HA, Scheele GA, eds. The exocrine pancreas: biology, pathobiology, and disease. New York: Raven Press, 1993: 219-51.

14 Gorelick FS, Matovcik LM. Lysosomal enzymes and pancreatitis [editorial]. Gastroenterology 1995; 109: 620-5.

15 Colomb E, Figarella C. Comparative studies on the mechanism of activation of the two human trypsinogens. Biochim Biophys Acta 1979; 571: 343-51.

16 Haverbeck BJ, Dyce B, Bundy H, Edmondson HA. Trypsin, trypsinogen and trypsin inhibitor in human pancreatic juice. Am f Med 1960; 29: 424-33.

17 Kassel B, Kay J. Zymogens of proteolytic enzymes. Science 1973; 180: 1022-7.

18 Krims PE, Pandol SJ. Free cytosolic calcium and secretagogue-stimulated initial pancreatic exocrine secretion. Pancreas 1988; 3: 383-90.

19 Leach SD, Modlin IM, Scheele GA, Gorelick FS. Intracellular activation of digestive zymogens in rat pancreatic acini. F Clin Invest 1991; 87: 362-6.

20 Bruzzone R. The molecular basis of enzyme secretion. Gastroenterology 1990; 99: 1157-76.

21 Gukovskaya A, Pandol S. Nitric oxide production regulates cGMP formation and calcium influx in pancreatic acinar cells. Am f Physiol 1994; 266: G350-6.

2 Slimak GG, Stark HA, Egan JJ, Jensen RT, Gardner JD. Effect of verapamil on the cyclic AMP-mediated pathway for amylase secretion in rat pancreatic acini. Pancreas 1993; 8: $212-9$.

23 Petersen OH, Gallacher DV. Electrophysiology of pancreatic and salivary acinar cells. Annu Rev Physiol 1988; 50: 65-81.

24 Mössner J, Schwarz J, Fischbach W. Influence of "calcium ${ }^{2+}$ channel blockers" on exocrine pancreatic secretion by isolated rat acini. Res Exp Med 1988; 188: 255-65.

25 Frick TW, Mithöfer K, Fernández-del Castillo C, Rattner DW, Warshaw AL. Influence of verapamil and nifedipine on cerulein, secretin and A23187 stimulated rat pancreatic on cerulein, secretin and A23187 stimulated rat pancreatic
acini: effect of elevated extracellular calcium. Digestion acini: effect of elev.

26 Gardner JD, Jensen RT. Receptors for secretagogues on pancreatic acinar cells. In: Go VLW, DiMagno EP, Gardner JD, Lebenthal E, Reber HA, Scheele GA, eds. The exocrine pancreas: biology, pathobiology, and disease. New York: Raven Press, 1993: 151-66. 